\title{
Genome-wide analysis of the rice PPR gene family and their expression profiles under different stress treatments
}

\author{
Guanglong Chen ${ }^{1}, \mathrm{Yu} \mathrm{Zou}^{1}$, Jihong $\mathrm{Hu}^{2}$ and Yi Ding ${ }^{1 *}$ (D)
}

\begin{abstract}
Background: Pentatricopeptide-repeat proteins (PPRs) are characterized by tandem arrays of a degenerate 35-aminoacid (PPR motifs), which can bind RNA strands and participate in post-transcription. PPR proteins family is one of the largest families in land plants and play important roles in organelle RNA metabolism and plant development. However, the functions of PPR genes involved in biotic and abiotic stresses of rice (Oryza sativa L.) remain largely unknown.

Results: In the present study, a comprehensive genome-wide analysis of PPR genes was performed. A total of 491 PPR genes were found in the rice genome, of which 246 PPR genes belong to the P subfamily, and 245 genes belong to the PLS subfamily. Gene structure analysis showed that most PPR genes lack intron. Chromosomal location analysis indicated that PPR genes were widely distributed in all 12 rice chromosomes. Phylogenetic relationship analysis revealed the distinct difference between the P and PLS subfamilies. Many PPR proteins are predicted to target chloroplasts or mitochondria, and a PPR protein (LOC_Os10g34310) was verified to localize in mitochondria. Furthermore, three PPR genes (LOC_ Os03917634,LOC_Os07g40820,LOC_Os04g51350) were verified as corresponding miRNA targets. The expression pattern analysis showed that many PPR genes could be induced under biotic and abiotic stresses. Finally, seven PPR genes were confirmed with their expression patterns under salinity or drought stress.

Conclusions: We found 491 PPR genes in the rice genome, and our genes structure analysis and syntenic analysis indicated that PPR genes might be derived from amplification by retro-transposition. The expression pattern present here suggested that PPR proteins have crucial roles in response to different abiotic stresses in rice. Taken together, our study provides a comprehensive analysis of the PPR gene family and will facilitate further studies on their roles in rice growth and development.
\end{abstract}

Keywords: Rice (Oryza sativa L.), Pentatricopeptide-repeat protein, miRNA, Expression patterns, Salinity or drought stress

\section{Background}

Pentatricopeptide repeat (PPR) proteins are a group of proteins that contain tandem repeats of degenerate 35-amino-acid motifs (PPR motifs) [1, 2], which play an important role in plant growth and development. Since the first PPR protein was recognized and characterized in the Arabidopsis thaliana genome sequence [3], many PPR proteins have been identified in plants. As RNA-binding proteins, PPR proteins participate in posttranscriptional processes including RNA editing [4-6], splicing [7], stability [8], cleavage [9], degradation [10], and translation [11]. A

\footnotetext{
*Correspondence: yiding@whu.edu.cn

'State Key Laboratory of Hybrid Rice, Department of Genetics, College of Life Sciences, Wuhan University, Wuhan 430072, China

Full list of author information is available at the end of the article
}

study has shown that the structure of the canonical PPR motif (P motif) is a hairpin of two $\alpha$-helices [12]. A PPR motif can recognize a single RNA nucleotide [12, 13], and an array of PPR domains can recognize special singlestranded RNA targets. In contrast to CRISPR gene editing at the DNA level, PPR-RNA interactions may become another editing alternative at the post-transcriptional level $[1,14]$.

Variants of the P motif include the L (long) motif and $S$ (small) motif. Based on the P, L and S motifs, PPR proteins can be divided into two subfamilies, P and PLS [4]. The PLS subfamily usually has an E or DYW domain in the C-terminal region [1]. Furthermore, the PLS subfamily can also be divided into three subgroups, including the PLS subgroup, E subgroup and DYW subgroup. Recently, 
a study on the structural motifs had redefined 10 different variants of the $\mathrm{P}$ motif in plant proteins, including one canonical P motif and nine P-like motifs (P1, P2, L1, L2, S1, S2, SS, E1 and E2) [15]. Therefore, P subfamily proteins contain tandem arrays of P motifs without other PPR motifs, while PLS subgroup proteins only contain varied PPR motifs, sometimes also with a non-PPR motif, DYW.

The number of PPR proteins is relatively large in many land plants compared with other eukaryotic organisms. For example, there are $441 P P R$ genes in Arabidopsis thaliana [4], and 471 PPR genes in tomato [16]. Surprisingly, the lycophyte Selaginella moellendorffii has 1670 PPR genes [17]. However, only 6, 2 and 2 PPR proteins were found in Homo sapiens, Caenorhabditis elegans and Drosophila, respectively $[2,4]$.

Studies have shown that most PPR proteins are targeted to mitochondria or chloroplasts and the function of some PPR proteins was elucidated to be associated with chloroplast, seed development, and fertility [1, 2]. It was reported that the nuclear OGR1 gene encoded a DYW- PPR protein, which is essential for mitochondria, and the of ogr1 mutant exhibited delayed seed germination and sterility [18]. The well-known function of some PPR proteins is acting as $R f$ (restorer of fertility) genes associated with cytoplasmic male sterility (CMS) of plants. Many PPR genes play the roles of restoring fertility in land plants, such as RFL2 in Arabidopsis [13], Rf1 in sorghum (Sorghum bicolor L.) [19], CaPPR6 in pepper (Capsicum annuuml.) [20] and RF592 in petunia [21]. Previous studies revealed that CMS is caused by the accumulation of the ORF79 protein and can be restored by two PPR proteins, Rf1a and Rf1b, in BT-type cytoplasmic male sterile rice (Oryza sativa L.), [22, 23]. However, most Rf-related $P P R$ genes belong to the P subfamily, which lacks the E/DYW motif [24].

PPR proteins play diverse and important roles in plant developmental processes and responses to biotic and abiotic stresses. For instance, SOAR1, an Arabidopsis cytosol-nucleus dual-localized PPR protein, was reported to be involved in ABA signaling and tolerance to drought, salinity or cold stress [25]. In addition, in Arabidopsis, five mitochondrial PPR proteins, PPR40 [26], ABO5 [27], SLG1 [28], PGN [29], and SLO2 [30], were reported to be involved in abiotic stress, including salt or drought stress responses. In rice, OsV4 encoding a PPR protein is required for chloroplast development in early stages under cold stress [31]. A novel thermosensitive chlorophyll-deficient mutant, $t c d 10$, encoding a PPR protein (LOC_Os10g28600) was also reported to be required for chloroplast development and photosynthesis in rice under cold stress [32]. However, few studies on $P P R$ genes of rice involved in salinity and drought stress have been reported.

In the present study, we characterized the $P P R$ genes in the rice genome with the report of redefining the structural of PPR motifs and analyzed the chromosomal arrangement, genes structure and the consensus sequence of PPR motifs as well as the subcellular localization. The expression patterns of the PPR genes in response to biotic and abiotic stresses were also analyzed, especially, under salt and drought stresses. Furthermore, the expression patterns were examined by quantitative real-time RT-PCR. These results will provide a biological reference for further elucidating the role of $P P R$ genes in rice.

\section{Results}

Identification of PPR genes in the rice genome

A total of 491 PPR genes were identified in the rice genome in this study (Additional file 1: Table S1). First, we identified 477 PPR genes in the RGAP and RAP-DB database at the beginning of the analysis. This number corresponded with that of previous reports [33]. Second, 14 PPR genes were found by comparing our result with those of Cheng et al. [15]. Combined the two results, there should be a total of 491 PPR genes in the rice genome. The 491 PPRs contained 246 P-class and 245 PLS-class members based on the proteins structures. Furthermore, there were $90 \mathrm{E}$ and 131 DYW sub-groups in the PLS subfamily, respectively (Fig. 1a and Additional file 1: Table S1). The numbers of $P P R$ genes in rice genome were higher than the 105 in moss (89 P-type and 16 PLS-type) [34], and 450 in Arabidopsis thaliana (251 P-type and 199 PLS-type) [33], and were relatively close to the 471 in tomato (233 P-type and 238 PLS-type) [16] and 486 in foxtail millet (263 P-type and 223 PLS-type) [17] (Fig. 1b and Table 1).

\section{Structure analysis of PPR proteins}

The arrangement of PPR motifs in rice obeyed the rules that the $\mathrm{P}$ class contained a series of canonical P motifs and the PLS-class had tandem repeat P-like motifs (Additional file 2: Figure S1A). Most PLS subfamily proteins were arranged in the manner of P1-L1-S1, or P2-L2-S2 and an E or DYW domain in the C-terminal region. In our study, only 9 PPR proteins (LOC_Os01g55290, LOC_Os01g62400, LOC_Os03g18620, LOC_Os04g21470, LOC_Os06g44820, LOC_Os07g36450, LOC_Os10g35650, LOC_Os11g03200, LOC_Os12g02950) contained two P motifs, while LOC_Os04g43430 had 28 motifs, including 27 P-like motifs and one DYW motif.

To obtain consensus sequences of motifs, we performed WebLogo [35] with default parameters using all the sequences of each PPR motif. Most P1 and P2 motifs started with two valines (Val, V) and ended with proline (Pro, P) and aspartic acid (Asp, D) (Additional file 2: Figure S1B). P1 and P2 were very similar. Glycine (Gly, G) was in all motif sequences at 15 th position, while most motifs possessed glutamic acid (Glu, E) in 18th and 19th position. Alanine (Ala, A) was shown at the 20th position in most PPR motif. Each motif contained methionine (Met, M) in 


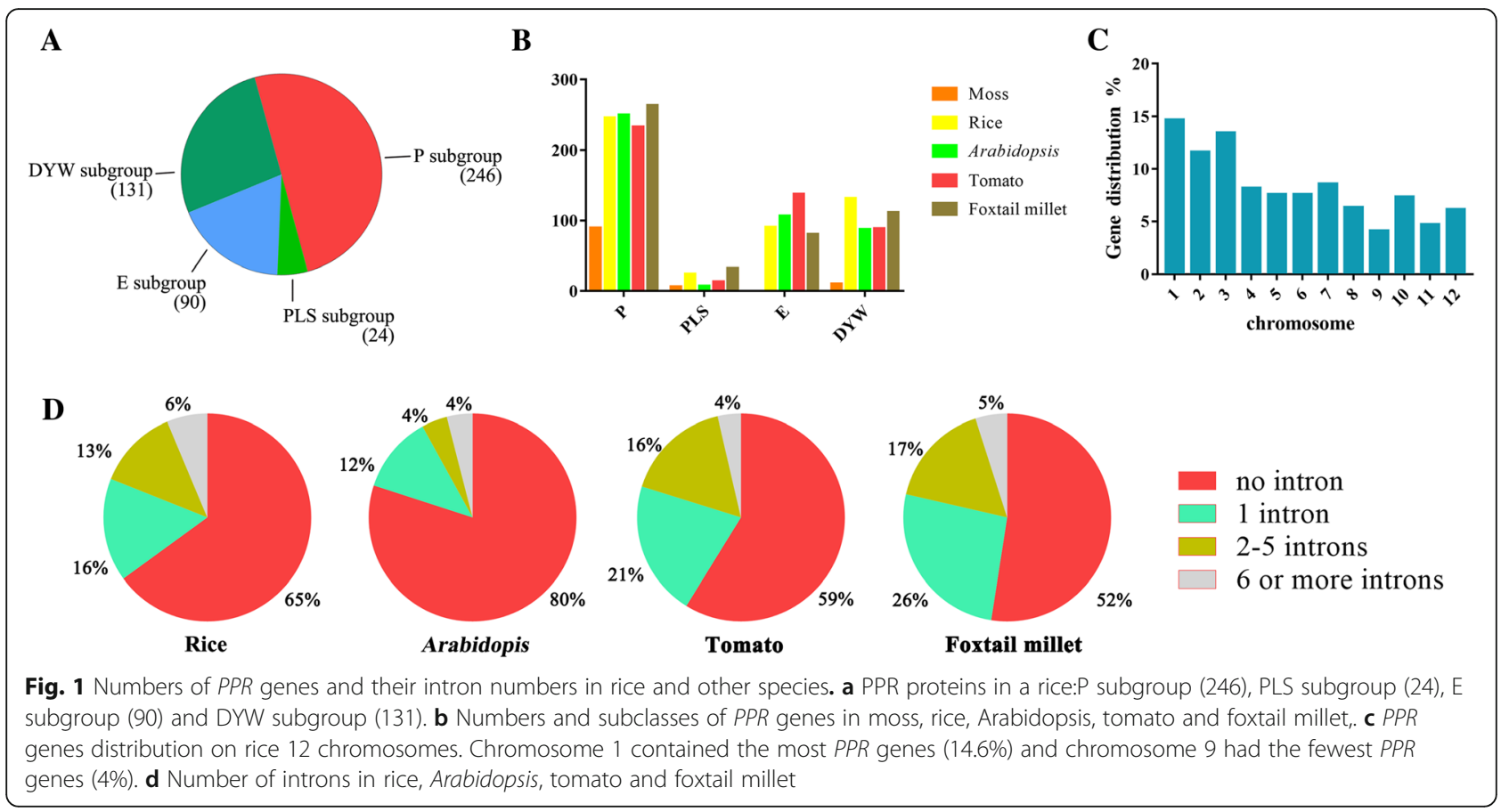

the 27th position except L1 with V and E1 with leucine (Leu, L). From the 1 st to the 12th in the P1 motif, there were 12 amino acid residues that were same as in the P2 and SS motifs. The consensus sequence is similar to that obtained by using PPR motif sequences from 41 representative genomes [15].

\section{Chromosomal localization and gene structure analysis}

Our study showed the 491 PPR genes were widely and unevenly distributed on all 12 rice chromosomes (Fig. 1c and Additional file 2: Figure S2). There were 72 PPR genes on chromosome 1 , the largest chromosome of the rice genome. The lowest number of PPRs was found on chromosome 9, which only possessed 20 PPR genes. Sixty-six PPR genes mapped on chromosome 3 , and fifty-seven genes in chromosome 2. We analyzed the sequence of $P P R$ genes and their coding sequences, and found that the majority of $P P R$ genes were intron-less (Fig. $1 \mathrm{~d}$ and Additional file 2: Figure S3). More than 65\% (319/491) of rice PPR gene ORFs (open reading frame) contained a single exon, $16 \%$ (79/491) had one intron, and only $19 \%$ genes had more than one intron (Fig. 1d). The result was similar to the

Table 1 The number of PPR proteins in rice and other species

\begin{tabular}{llllll}
\hline Plant species & Total & $P$ & PLS & $E$ & DYW \\
\hline Moss & 105 & 89 & 6 & 0 & 10 \\
Rice & 491 & 246 & 24 & 90 & 131 \\
Arabidopsis & 441 & 241 & 6 & 107 & 87 \\
Tomato & 471 & 233 & 13 & 137 & 88 \\
Foxtail millet & 486 & 263 & 32 & 111 & 80 \\
\hline
\end{tabular}

structure of PPR genes in Arabidopsis, in which approximately $80 \%$ PPR genes had no intron and $12 \%$ had only one intron. Approximately 58\% and 52\% PPR genes contained only one exon in tomato and foxtail millet, respectively. Most $P P R$ genes were intron-less in all $P P R$ gene families. It had been presumed that the $P P R$ genes family was derived from amplification by transposition $[4,33]$. Some intron-rich $P P R$ genes would represent "ancient" $P P R$ genes and were duplicated by reverse transcription and integrated into the genome, which might create novel genes.

\section{Phylogenetic and syntenic analysis of rice $P P R$ proteins}

Using the neighbor-joining (NJ) method based on the full-length amino acid sequences of 491 rice PPR proteins, the phylogenetic tree was constructed. The tree was classified into two distinct subfamilies ( $\mathrm{P}$ and PLS subfamily) (Fig. 2a). However, several PPR members of the PLS subfamily were clustered with the P subfamily, which is consistent with the results from the poplar phylogenetic analysis in which some PPR proteins possessed the PLS structure, but were clustered into the P subfamily [36].

To analyze the evolutionary relationships among PLS subgroup genes, we performed multiple sequence alignment of 24 from rice, 6 form Arabidopsis, 6 from moss, 13 from tomato and 32 from foxtail millet (Table 1) to generate a phylogenetic tree (Additional file 1: Figure S4). Most of these PPRs were clustered with a group in the same species and the moss PPRs were obviously divergent from other plants. However, some PPRs from rice, Arabidopsis and tomato were mixed, suggesting that these PPR members were 




homologous. Furthermore, we evaluated the syntenic relations of PPR genes using MCScanX program. A total of 276 $P P R$ genes were located within syntenic blocks on all rice chromosomes (Fig. 2b).

\section{Subcellular localization of PPR proteins}

Most reported $P P R$ genes play roles in mitochondria or plastids. Therefore, we predicted their subcellular localization using TargetP 1.1 [37] and Predotarv.1.04 [38] in the study. We obtained similar results with the two programs, which predicted that most PPR proteins targeted either mitochondria or plastids. Using TargetP, approximately 54\% PPR proteins were predicted to target mitochondria and $28 \%$ to chloroplast, while Predotar predicted $44 \%$ to mitochondria and $22 \%$ to plastid (Additional file 1: Table S2). Combining the two results, we found that more than one-half of the P-class proteins were located in the mitochondria and approximately $28 \%$ were in plastids (Fig. 3a). For PLS-class proteins, approximately $50 \%$ were predicted in plastids and $30 \%$ in mitochondria. E-class and DYW-class proteins had a similar distribution in subcellular localization, with half in mitochondria and $30 \%$ in plastids (Fig. 3a). Furthermore, we used
PPR-GFP fusion proteins to detect their subcellular localization in rice protoplasts. The protein encoded by the gene LOC_Os10g34310 was indeed located in mitochondria (Fig. 3b). The PPR-GFP fusion protein was observed with green fluorescence in mitochondria that were treated with MitoTracker Red and could be detected with red fluorescence by a confocal laser scanning microscope. As a result, the $P P R$ gene (LOC_Os10g34310) was verified to localize in mitochondria, which was consistent with the result predicted by TargetP (Fig. 3b).

\section{PPR proteins as the target genes of miRNAs in rice}

PPR proteins could be the target genes of some miRNAs, which play diverse roles in plant development, including fertility transition [39] and abiotic stress [40]. In the present study, we identified three miRNAs and their corresponding targets (PPR genes) and validated the expression patterns using qRT-PCR (Fig. 4). The results showed that osa-miR1862d had a higher expression in shoot and P3 stages, while LOC_Os03g17634 was expressed in shoot and P3 stages with lower expression (Fig. 4a, and d); osa-miR396a-5p was mainly expressed in panicles, and LOC_Os07g40820 was predominantly expressed in seedling 


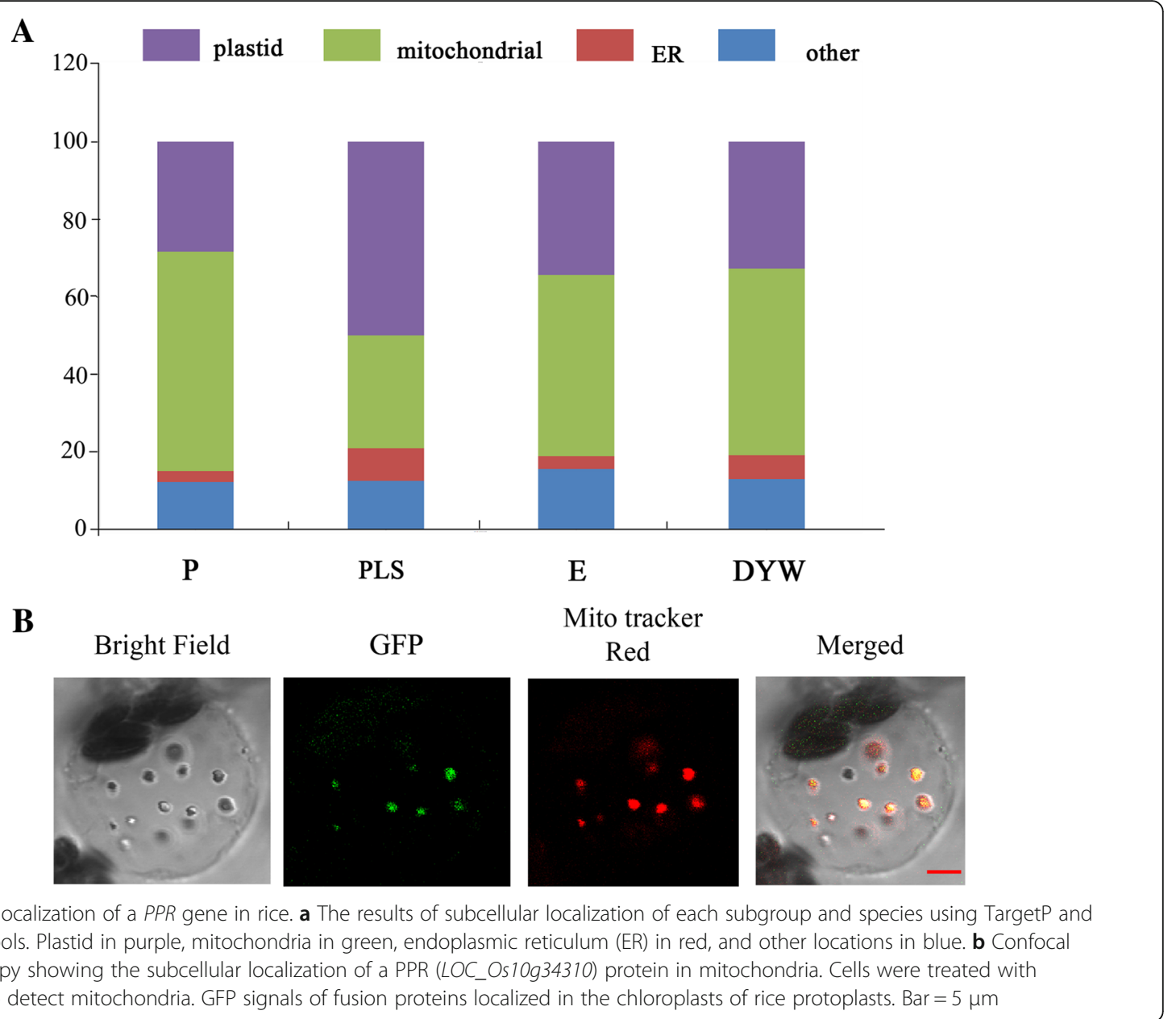

(Fig. 4b, and e). The expression level of osa-miR444b.2 was highest in the P4 stage, but LOC_OsO4g51350 was mainly expressed in leaves (Fig. 4c, and f). These results future showed negative correlations between expression levels of miRNAs and their corresponding PPR target genes at the relative expression level.

In this study, a total of 49 miRNAs were predicted to target 54 PPR genes (Additional file 1: Table S3). Compared with previous studies, we found that some miRNAs targeted $P P R$ genes were involved in rice male sterility, and some miRNAs had differential expression in the rice male sterile lines Meixiang A and Wuxiang S [39, 41], indicating their roles in the regulation of pollen abortion and participation in rice male sterility.

\section{Expression patterns of $P P R$ genes}

Gene expression profiles could provide clues for functional studies. We used FPKM values to represent PPR gene expression in different tissues and organs of rice in this study. Based on hierarchical clustering, the Log2based RNA-seq value was used to create the heat map, which represented the relative expression of $491 P P R$ genes in different developmental stages (Additional file 2: Figure S5 and Additional file 1: Table S4). Our results showed that the PPR genes had different expression levels in various organs and tissues. Most $P P R$ genes were expressed in young leaves and panicles, showing a lower expression in endosperm after 25 days of pollination. Then, we used qRT-PCR to verify the RNA-seq data (Fig. 5) and revealed that the genes LOC_OsO3g19650 and LOC_Os04g49350 had high expression levels in shoot and seedling, but were expressed at an extremely low level in other examined organs (Fig. 5a). The genes LOC_Os05g28500 and LOC_Os12g1210 were specifically expressed in seedling and 20-day-old leaves (Fig. $5 \mathrm{~b}$, and c). The remaining results are as follows: Genes LOC_Os03g53490, LOC_08g42610, and LOC_12g44170 were mainly expressed in leaves and were detected in panicles and seeds with lower expression. Gene LOC_Os01g12180 was expressed in all examined organs (except at pre-EI stage), while LOC_Os04g14130 exhibited less and less expression as the rice grew. Those results revealed the potential functions of $P P R$ genes in different rice development stages. 


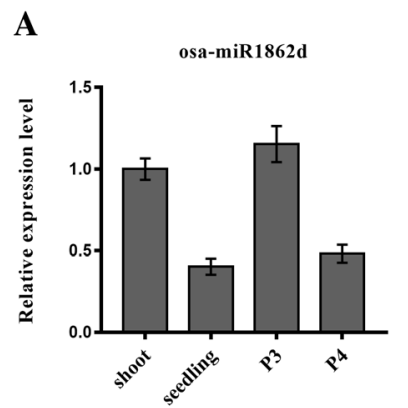

D

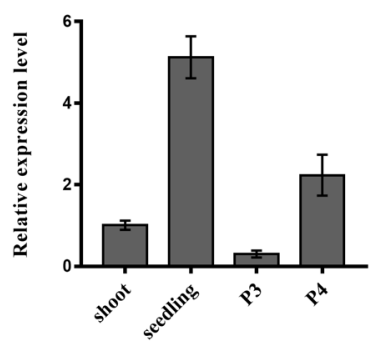

$\mathbf{B}$

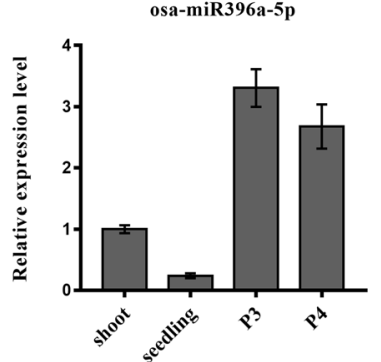

$\mathbf{E}$

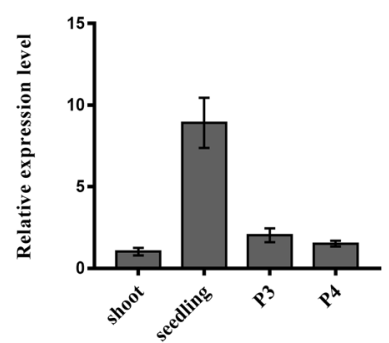

C

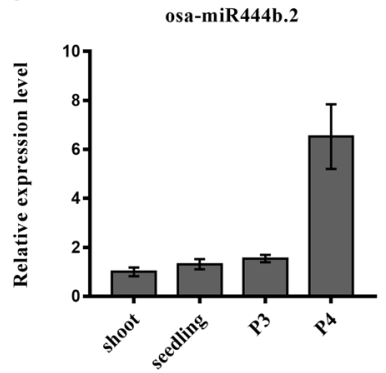

$\mathbf{F}$

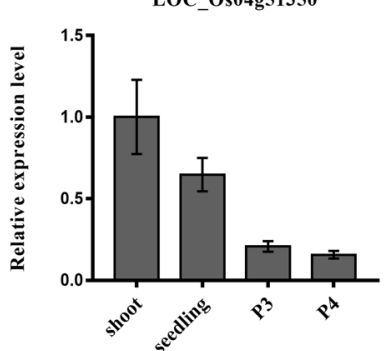

Fig. 4 Validation and expression of selected miRNAs and their target PPR genes. Relative expression levels of three PPR genes as the targets of miRNAs in rice shoot, seeding, P3 and P4, (a, d) osa-miR1862d (a) and its target (LOC_Os03g17634)(d). (b, e) osa-miR396a-5p (b) and its target (LOC_Os07g40820) (e). (c, f) osa-miR444b.2 and its target (LOC_Os04g51350)

\section{A}

.$-60.0 \quad 0.0 \quad 6.0$



LOC_Os01g12810
LOC-Os0391960
LOC_Os04g49350

B



C

$\begin{array}{rrr}-4.0 & 4.0 & 4.0\end{array}$

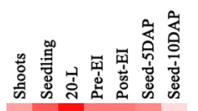

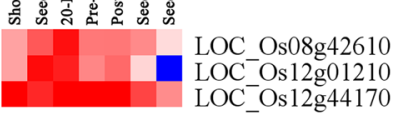

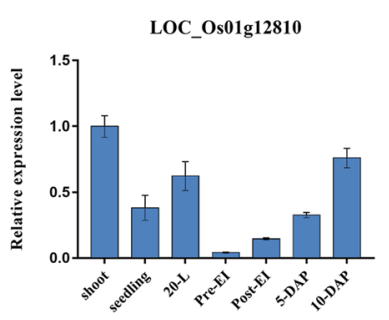

LOC_Os03g53490

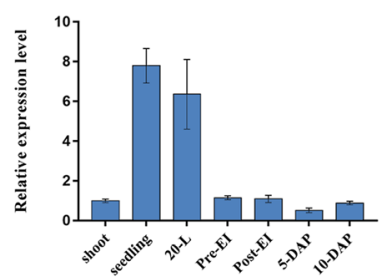

LOC_Os08g42610

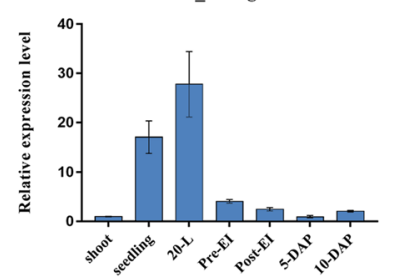

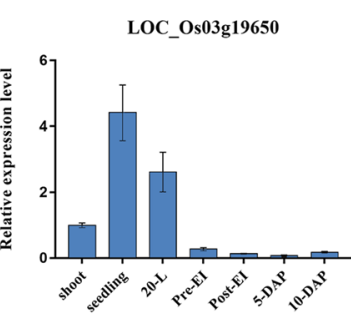
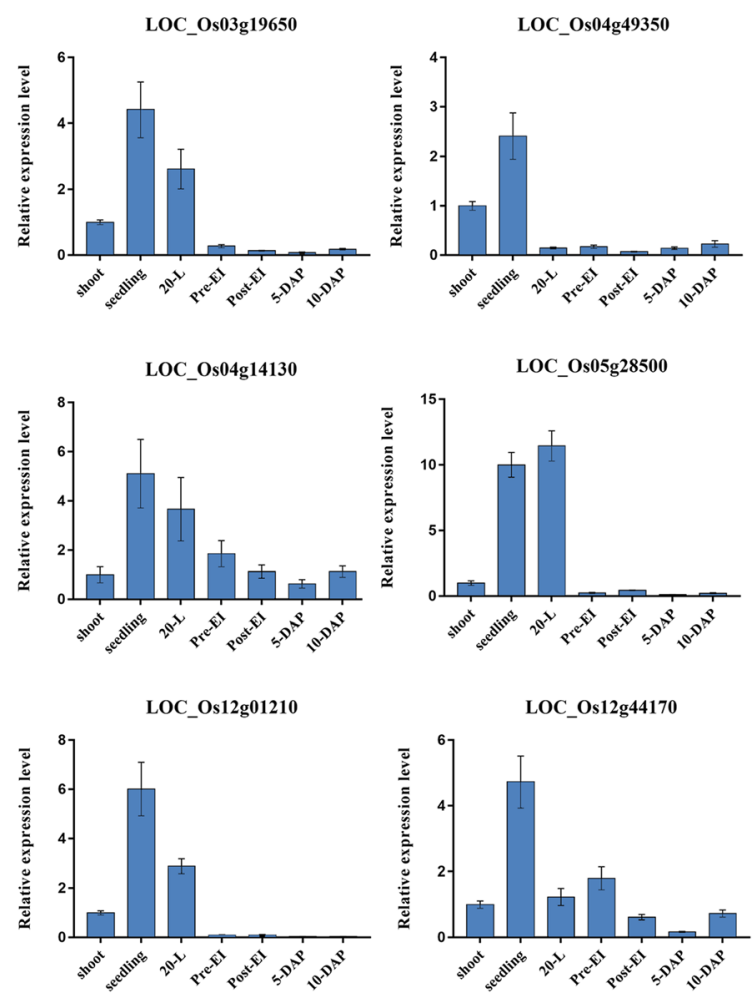

LOC_Os12g44170

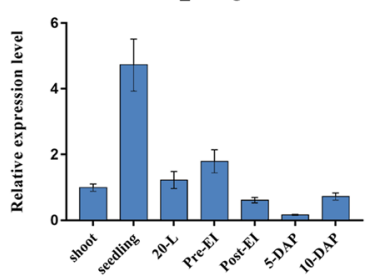

Fig. 5 qRT-PCT validation of nine PPR gene expression patterns. a Heatmap and relative expression levels of LOC_Os01g12810, LOC_Os03g19650 and LOC_Os04g49350. b Heatmap and relative expression levels of LOC_Os03953490, LOC_Os04g14130 and LOC_Os05g28500. c Heatmap and relative expression levels of LOC_Os08g42610, LOC_Os12g01210 and LOC_Os12g44170 


\section{Expression regulation of $P P R$ genes under biotic and abiotic stresses}

Previous studies revealed that many PPR proteins play important roles in response to biotic and abiotic stresses in poplar [36]. However, few reports of PPRs involved in these stresses in rice have been documented. In this study, to determine their potential roles to respond to various environmental stresses, we investigated the expression profiles of rice $P P R$ genes under different treatments using high-throughput sequencing data. These stresses included rice stripe virus (RSV), bacterial blight disease, rice blast and phosphorus, cadmium, and cold stresses as well as drought and salinity stresses (Fig. 6). Our expression profiling results showed that many PPR genes were induced under the stresses, especially in the bacterial blight disease, cold and cadmium stresses (Fig. 6b, f, and g). Interestingly, some PPRs, including LOC_Os02g46980 and LOC_Os07g09370 were differentially expressed in both cold, drought, salt stresses and RSV, rice blast infection, respectively (Fig. 6 and Additional file 1: Table S5), indicating that these $P P R$ genes might participate in many stress response processes in rice.

\section{Expression regulation of $P P R$ genes under salt and drought stresses}

To determine the response of $P P R$ genes to abiotic stress, the RNA-seq data of rice subjected to the treatment of salt and drought stresses [42] were analyzed in the study. The results revealed that a total of $75 P P R$ genes were up-regulated $(>2)$ under salt stress conditions and $73 P P R$ genes were up-regulated under the drought stress conditions compared with the control (Fig. 7a). We randomly chose seven PPR genes and verified their expression patterns using qRT-PCR under salt and drought stresses (Fig. 7). Under salt stress condition, gene LOC_Os05g30240 showed a slight up-regulated expression. Both gene LOC_Os05g47510 and gene LOC_Os11g37330 were more highly expressed at $24 \mathrm{~h}$ and $72 \mathrm{~h}$ after $200 \mathrm{mM} \mathrm{NaCl}$ treatment (Fig. 7b). Under drought stress [10\% $(w / v)$, PEG6000], the genes LOC_Os02g46980 and LOC_Os04g01990 showed

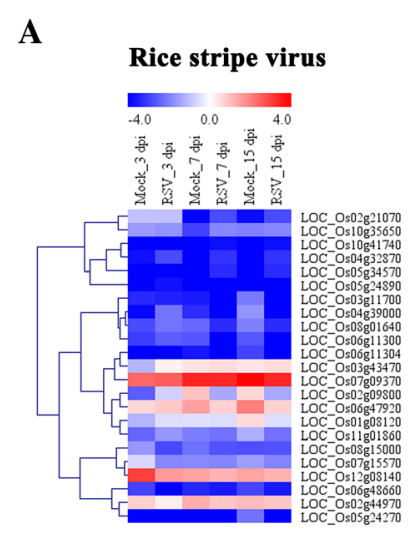

$\mathbf{E}$
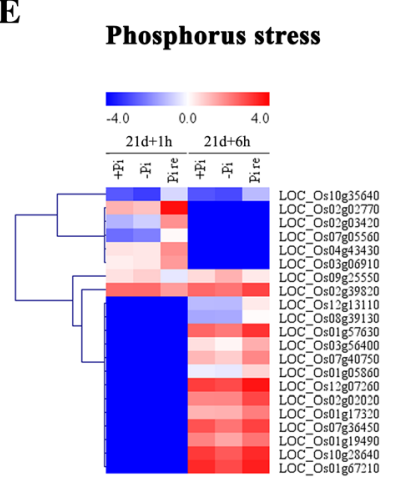

B

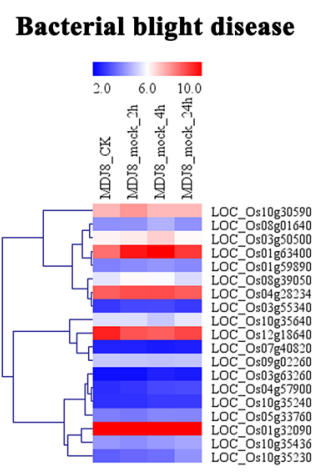

$\mathbf{F}$

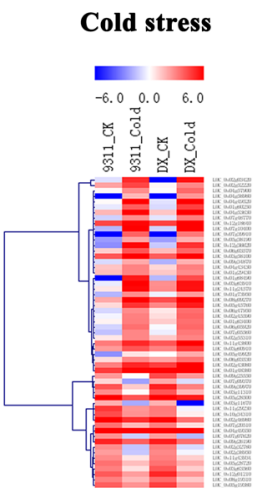

C

\section{Rice blast disease}

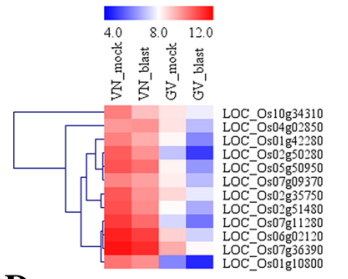

D

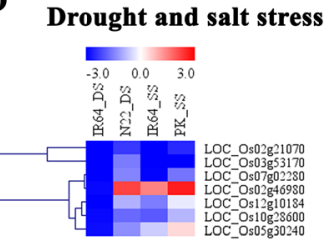

G Cadmium stress

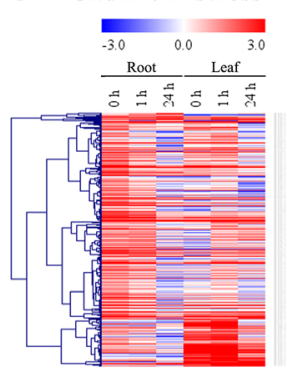

Fig. 6 Expression profiles of the PPR genes in response to different stresses. All heat maps were generated using MeV4.9 software with log2transformed FPKM values. a Expression profiles of PPR genes in rice infected by rice stripe virus (RSV). Mock means control and dpi means days post inoculation. $\mathbf{b}$ Expression profiles of PPR genes in rice infected with bacterial blight disease. MDJ8 represents Japonica rice cultivar Mudanjiang8. c Expression profile of PPR genes in rice infected by rice blast disease. VN and GV represent a blast-tolerant cultivar and susceptible cultivar, respectively. $\mathbf{d}$ Expression profiles of PPR genes in rice under drought and salt stresses, respectively. N22 is a drought-tolerant cultivar. PK is a salinity-tolerant rice cultivar and IR64 is a susceptible cultivar. e Expression profiles of PPR genes in rice under phosphorus stress. +Pi, - $\mathrm{Pi}$ and Pire represent control, phosphate starvation and recovery, respectively. $\mathbf{f}$ Expression profiles of PPR genes in rice under cold stress. 9311 and DX (Dongxiang wile rice) are two rice varieties, and CK is the control condition of cold. $\mathbf{g}$ Expression profiles of PPR genes in rice under cadmium stress. Rice was treated with cadmium for $1 \mathrm{~h}$ and $24 \mathrm{~h}$, and root and shoot were collected for this experiment 




significant up-regulation compared with the control, while LOC_Os04g46010 exhibited increase expression only at $24 \mathrm{~h}$ (Fig. 7c). Those PPR genes might be involved in salt stress or drought stress responses. LOC_OsO3g53170 also showed obvious up-regulation expression under the two stresses condition, indicating that it might participate both in salt and drought stress tolerance.

The cis-elements in promoter regions are closely associated with gene transcription and their response to stress. Therefore, $1.5 \mathrm{~kb}$ upstream sequences from the ATG initiation code were downloaded and analyzed using PlantCARE databases [43]. Some stress-responsive cis-acting elements were showed in promoter regions of the seven PPR genes, including ABRE, ARE, HSE, Skn-1_motif, TGACG motif and 5' UTR Py-rich stretch (Fig. 8). All these elements had an important role in the regulation of gene transcription induced by biotic and abiotic stress. Among the seven PPR genes, the LOC_Os05g47510 promoter only had seven elements, while LOC_Os04g46010 had maximum20 elements. Almost every promoter region in the PPR genes contained ABRE, Skn-1_motif and TGACG motif. Although the correlation between cis-elements and response of genes in stresses conditions require more experimental investigation, these results revealed the stress-responsive nature of $P P R$ genes.

\section{Discussion}

The PPR protein family is a large family that has been identified in many land plants. Previous research has shown that there were $477 P P R$ genes in rice [33]. In the present study, we identified $491 P P R$ genes in the rice genome. Furthermore, to understand the function, structure, and evolution of these genes, we analyzed the gene distribution in the genome, the gene structure and the subcellular location, performed functional analysis as miRNA targets, constructed a phylogenetic tree, and performed the gene expression analysis under different stresses. Our results showed that the function of $P P R$ 




Fig. 8 The promoter analysis in the seven PPR genes. Different cis-elements were indicated by different color symbols and placed in their relative position on the promoter. Symbols presented above the line indicate the elements at the forward strand, while those below indicate the reverse strand. The ABA-responsive element (ABRE), light response cis-acting element (ACE), light response module (AE-box), anaerobic induction element (ARE), auxin responsive element (AuxRR-core), fungal elicitor responsive element (BOX-W1), gibberellin-responsive element (GARE), heat shock element (HSE), low temperature responsive element (LTR), MYB-binding site (MBS), endosperm expression required element (Skn-1_motif), salicylic acid responsive element (TCA), Methyl jasmonate-responsive element (TGACG motif), defense and stress responsive element (TC-rich repeat), and element conferring high transcription level (5' UTR Py-rich stretch) were analyzed

genes is varied during the development and stress response in rice.

In our evolutionary analysis, PPR proteins family in rice can be divided into P and PLS subfamilies based on the arrangement of ten PPR motifs and one DYW motif. Phylogenetic analysis also showed distinct differences between the two groups of proteins, except that some PLS proteins mixed with the P subfamily (Fig. 2a). These findings were similar to the phylogenetic relationship of poplar, which also had two distinct subfamilies, except that 7 PLS proteins clustered into the P subfamily [36]. We analyzed the consensus sequences of ten PPR motifs, including $1 \mathrm{P}$ motif and 9 P-like motifs (Fig. 2). There were extremely similar to the sequence of other species that were previously reported [15], which indicates the conservation of PPR proteins during the evolution among plants.

In the present study, gene structure analysis revealed that most PPR genes were intron-less; $65 \%$ of PPR genes contained no intron and $16 \%$ possessed one intron, while only 7\% of PPR genes had 5 or more introns. In Arabidopsis, more than $80 \%$ of $P P R$ genes contained a single exon, and only $12 \%$ contained one intron $[14,33]$. The intron-less nature of the majority of $P P R$ genes and the wide distribution of $P P R$ genes on chromosomes in land plants may reveal duplication event of $P P R$ genes. It had been presumed that $P P R$ genes family was derived from amplification by retro-transposition $[4,14,33]$. Synteny relationship of the PPR proteins in rice revealed that $276 P P R$ genes had synteny with other PPR genes in rice. LOC_Os11g01210 and LOC_Os12g01210 shared more than 1000 bp of the same sequence in their coding sequences. These results could prove that "ancient" PPR genes with some introns were amplified by reverse transcription and integrated into the genome, which resulted in a large number of intron-less $P P R$ genes in the genome with a wide distribution in all chromosomes.

Previous studies have shown that PPR proteins are RNA-binding proteins that play a major role in post-transcription via RNA editing, splicing, cleavage, stability or translation in mitochondria or plastids [1]. In maize, PPR10 proteins could stabilize RNAs by binding specific regions and blocking $5^{\prime}$ or $3^{\prime}$ degradation, which can promote translation efficiency. It could also activate translation of atpH RNA by preventing the formation of secondary structure and exposing ribosome-binding sites for translation [44]. It was hypothesized that maize PPR5 proteins prevent the formation of an RNA hairpin, which could mask a key cis-element for splicing of group II introns [45]. Several PPR-encoding Rf proteins induced the cleavage of sterility-associated mitochondrial RNAs. Those proteins induced the formation of adjacent $5^{\prime}$ and 3 ' termini, which stimulate site-specific endonucleolytic cleavage [46]. PLS PPR proteins are almost exclusively associated with C-to-U RNA editing, which always alters the coding potential of the transcript. Although the precise mechanism of PRR editing activity is not well documented, it had been proved that multiple-organellar RNA-editing factor (MORF) proteins were required for editing with PPR proteins and other factors [47].

PPR proteins could be the target genes of some miRNAs that regulate in abiotic stress responses and fertility restore [40]. A total of 49 miRNAs were predicted to target 64 PPR genes in this study (Additional file 1: Table S3). One target of osa-miR1425 is the $R f-1$ gene, which not only leads to an increase in the number of potentially fertile pollen grains but also enhances cold tolerance in 
hybrid rice $[48,49]$. In our study, we validated three $P P R$ genes targeted by corresponding miRNAs (osa-miR1862d, osa-miR396a and oss-miR444b.2) (Fig. 5). Compared to the WXS (F) cultivars, osa-miR1862d and oss-miR444b.2 were both up-regulated in P2 (mother cell formation stage) and P3(meiosis stage) of the WXS (S). osa-miR396a appeared to be up-regulated in both P2 and P3 stage of WXS (S) [39]. The expression changes of the miRNAs in the same stage of fertile and sterile rice were consistent with potential functions of target $P P R$ genes acting as fertility restorers. The results suggested that miRNAs and their target PPR genes might be related to male sterility and anther development during fertility transition.

In rice, dual-localized PPR protein OsPGL1 was preferentially expressed in leaves particularly in the four and five leaf and was essential for the chloroplast development in rice leaves [47]. A fertility restorer gene, Rf4, was expressed at the highest level in the anthers at the tri-cellular pollen stage, where the fertility restoration occurred (Table 2). Therefore, gene expression patterns would be able to reveal important clues for studying genes function. In this study, analysis of public data showed that $P P R$ genes in rice have temporal and spatial expression patterns. The results of real-time PCR showed that some PPR genes, including LOC_Os03g19650,LOC_Os04g49350,
LOC_Os05g28500 and LOC_Os12g01210 were predominantly or specifically expressed in young leaves (Fig. 6). In addition, the four genes were all predicted to locate in chloroplasts, indicating that they may be involved in leaf development. The genes LOC_Os01g12810, LOC_OsO4g14130 and LOC_Os12g44170 were also highly expressed at the stage of panicles and seed development. We inferred that those genes might participate in embryonic and seed development.

In previous studies, $P P R$ genes changed their expression under biotic and abiotic stress and regulated growth in many plants. In rice, WSL is localized to chloroplast and involved in abiotic stress response. Wsl mutant showed enhanced sensitivity to ABA, salinity, and sugar [50]. Another PPR protein OsV4 plays an important role during early chloroplast development under cold stress [31]. In this study, we analyzed the expression patterns of $P P R$ genes under different biotic and abiotic stresses (Fig. 7). The results showed that many $P P R$ genes were induced by stresses. Some $P P R$ genes had clearly up-regulation expression under phosphorus and cold stresses. The genes LOC_Os02g46980 and LOC_Os07g09370 were found differentially expressed in cold, drought, salt stresses and RSV, rice blast infection, respectively (Additional file 1 : Table S5), indicating that these PPR genes might participate in many processes and respond to different

Table 2 Some PPR genes reported in rice

\begin{tabular}{|c|c|c|c|c|c|}
\hline PPR Genes & MSU_Locus & localization & Function of gene & Phenomenon of Mutation & References \\
\hline OsPPR1 & LOC_Os09g24680 & chloroplast & $\begin{array}{l}\text { play a role in the chloroplast } \\
\text { biogenesis }\end{array}$ & albinism and lethality & $\begin{array}{l}\text { Gothandam et al. Plant } \\
\text { Mol Biol (2005) }\end{array}$ \\
\hline WSL & LOC_Os01g37870 & chloroplast & $\begin{array}{l}\text { affects chloroplast development } \\
\text { and abiotic stress response }\end{array}$ & $\begin{array}{l}\text { displays chlorotic striations early } \\
\text { in development and enhanced } \\
\text { sensitivity to ABA, salinity, and sugar }\end{array}$ & $\begin{array}{l}\text { Tan et al. Mol Plant } \\
\text { (2004) }\end{array}$ \\
\hline OsPPR6 & LOC_Os05g49920 & chloroplast & $\begin{array}{l}\text { regulates early chloroplast } \\
\text { biogenesis and participates in } \\
\text { editing of } n d h B \text { and splicing of } \\
y c f 3 \text { transcripts }\end{array}$ & albino leaves and seedling death & $\begin{array}{l}\text { Tang et al. Plant Mol } \\
\text { Biol (2017) }\end{array}$ \\
\hline OspTAC2 & LOC_Os03g60910 & chloroplast & $\begin{array}{l}\text { plays a critical role in } \\
\text { chloroplast development }\end{array}$ & albino and seedling-lethal & $\begin{array}{l}\text { Wang et al. J Genet } \\
\text { Genomics (2016) }\end{array}$ \\
\hline OsV4 & LOC_Os04g39970 & chloroplast & $\begin{array}{l}\text { plays an important role } \\
\text { during early chloroplast } \\
\text { development under cold stress }\end{array}$ & $\begin{array}{l}\text { albino phenotype and abnormal } \\
\text { chloroplasts at } 20^{\circ} \mathrm{C} \text { green leaves } \\
\text { and normal chloroplasts at } 32^{\circ} \mathrm{C}\end{array}$ & $\begin{array}{l}\text { Gong et al. J Integr Plant } \\
\text { Biol (2013) }\end{array}$ \\
\hline OGR1 & LOC_Os12g17080 & mitochondria & $\begin{array}{l}\text { essential for RNA editing } \\
\text { required for normal growth }\end{array}$ & $\begin{array}{l}\text { opaque seeds, delayed seed } \\
\text { germination, retarded growth, } \\
\text { dwarfism and sterility }\end{array}$ & Kim et al. Plant J (2009) \\
\hline Rfial Rf5 & LOC_Os10g35436 & mitochondria & $\begin{array}{l}\text { restore the fertility via cleavage } \\
\text { of atp6/orf79 mRNA. }\end{array}$ & $\begin{array}{l}\text { cannot restore male fertility in } \\
\text { BT-CMS }\end{array}$ & $\begin{array}{l}\text { Wang et al. Plant Cell } \\
\text { (2002) }\end{array}$ \\
\hline Rf4 & LOC_Os10g35240 & mitochondria & $\begin{array}{l}\text { reduce the expression of } \\
\text { orf } 352 \text { and restore the } \\
\text { fertility of WA-CMS }\end{array}$ & $\begin{array}{l}\text { cannot restore male fertility in } \\
\text { WA-CMS }\end{array}$ & $\begin{array}{l}\text { Tomohiko et al. Rice } \\
\text { (2014) }\end{array}$ \\
\hline OSPGL 1 & LOC_Os12g06650 & $\begin{array}{l}\text { dual-located in } \\
\text { mitochondria } \\
\text { and chloroplast }\end{array}$ & $\begin{array}{l}\text { involved in both chloroplast } \\
\text { RNA editing of } n d h D-878 \text { and } \\
\text { mitochondrial RNA editing of } \\
\text { ccmFc- } 543\end{array}$ & $\begin{array}{l}\text { exhibited pale green leaves at } \\
\text { all vegetative stages }\end{array}$ & $\begin{array}{l}\text { Xiao et al. J Exp Bot } \\
\text { (2018) }\end{array}$ \\
\hline PPS1 & LOC_Os12g36620 & mitochondria & $\begin{array}{l}\text { required for specific editing } \\
\text { sites in nad3 in mitochondria }\end{array}$ & $\begin{array}{l}\text { delayed development and partial } \\
\text { pollen sterility }\end{array}$ & $\begin{array}{l}\text { Xiao et al. New Phytol } \\
\text { (2018) }\end{array}$ \\
\hline
\end{tabular}


stresses in rice. Further qRT-PCR analysis validated that some genes were up-regulated under salt or drought stress (Fig. 7). The genes LOC_Os05g30240, LOC_Os05g47510 and LOC_Os11g37330 were induced by salt stress, while LOC_Os02g46980, LOC_Os04g01990 and LOC_Os04g46010 were highly expressed under drought than in normal conditions. LOC_OsO3g53170 had a significantly increased expression under both stresses.

Many studies showed that cis-elements were involved in the expression of genes under different stresses. In Arabidopsis, three NAC transcription factors bound to drought-responsive cis-element (MYC-like sequence) in ERD1 promoter and improved its drought stress tolerance [51]. A cis-acting element in the $5^{\prime}$-regions of the cor $15 a$ (cold-regulated) gene could be activated in response to low temperature, which was important for plants in cold resistance [52]. In our study, cis-element analysis results revealed that ABRE, Skn-1_motif and TGACG motif were found in the promoter regions of $P P R$ genes that had a higher expression under salt and drought stresses. Although the mechanism should be further explored, the preliminary analyses of these elements would be helpful for understanding the gene responses to different stresses.

\section{Conclusions}

In this study, we identified 491 rice PPR genes, which can be divided into four subgroups. Gene structure and distribution analysis showed that most PPR genes are intronless and widely distributed across all rice chromosomes. PPR proteins were predicted to be located in chloroplasts or mitochondria, where they were involved in the posttranscriptional modification. We also analyzed their phylogenetic and syntenic relationships, their functions as miRNA targets, and their expression patterns in different issues in rice. Furthermore, the expression patterns during different stages and expression profiles under salt and drought stress treatment were also elucidated and validated. The result suggested that PPR genes might play roles in rice response to environmental stresses. Taken together, our data will provide insight into the further study of $P P R$ genes function in rice.

\section{Methods}

\section{Plant materials and stress treatments}

Rice (Oryza sativa L. japonica cv. Nipponbare) seeds were grown in containers with sponges as supporting materials in sterile water at $28{ }^{\circ} \mathrm{C}$ with $24 \mathrm{~h}$ light. After 7 days, the seedlings were transferred into a paddy at Wuhan University $\left(30^{\circ} 34^{\prime} \mathrm{N} ; 114^{\circ} 17^{\prime}\right.$ E) under natural conditions. Plant materials for expression analysis were: (i) 7-day-old leaves (shoot), 15-day-old leaves (seedling) and 20-day-old leaves (20-L); (ii) panicle before emergence inflorescence and after emergence inflorescence, $5-10 \mathrm{~cm}$ panicles (P3) and 10-15 cm panicle (P4); (iii) 5 DAP and 10 DAP seeds.
The 14-day seedlings cultivated in containers were separately treated with two stress conditions: salt stress (200 mM NaCl) and drought stress [20\% (w/v)] (PEG $6000)$. Leaves of the treated samples were collected at 0,12 , 24,48 , and $72 \mathrm{~h}$. All materials were taken, quickly frozen in liquid nitrogen, and stored at $-80{ }^{\circ} \mathrm{C}$ until RNA extraction.

\section{Database screening and identification of $P P R$ genes}

Some databases were used to search $P P R$ genes in rice. First, BLASTP searches of the PPR domain, "PF01535" [4], was performed on the website of the Rice Genome Annotation Project (RGAP, http://rice.plantbiology.msu.edu/) to find PPR genes. Second, 'Pentatricopeptide repeat' was used as a keyword in a functional annotation search at the Rice Annotation Project Database (RAP-DB, http:// rapdb.dna.affrc.go.jp/). The results of the two searches were integrated and then redundant genes were discarded. Finally, the protein sequences were submitted to the PPR Database (http://www.plantppr.com/) [15] and protein structures were automatically analyzed. According to the results, proteins that had no PPR motif or only one PPR motif were discarded.

\section{Gene distribution and structure analysis}

All PPR gene loci were searched in the RDAP and DAP-DB database and their information including chromosome location and position. The map of genes distributed across chromosomes was created with Mapchart software in the study.

For gene structure analysis, the exon and intron structures of individual $P P R$ genes were illustrated using the Gene Structure Display Server (GSDS; http://gsds.cbi.pku.edu.cn/ ) by aligning the genomic DNA sequences with the corresponding cDNA sequences from the RADP and RAP-DB database.

\section{Consensus sequence of PPR motif analysis}

There were 10 PPR motifs in PPR proteins including one $\mathrm{P}$ motif and nine PPR-like motifs (P1, P2, L1, L2, S1, S2, SS, E1 and E2). All sequences of each motif were analyzed based on PPR proteins sequence and structure. The consensus sequence and distribution of amino acid residues at the corresponding positions in the PPR motif were generated using the WebLogo program with default parameters (http://weblogo.berkeley.edu/logo.cgi).

\section{Phylogenetic and synteny analysis}

Multiple sequence alignment of 491 PPR proteins from rice and 48 PPR proteins from other species, including Arabidopsis, moss, tomato and foxtail millet, was conducted using the MUSCLE method. A phylogenetic tree was conducted by the neighbor-joining (NJ) method with MEGA 7.0 [53] and bootstrap analysis of 1000 replicates.

All rice PPR protein sequences were searched against themselves using the BLASTp program with the E-value 
setting to $1 \mathrm{e}-10$. Then, the result file and the GFF files of the rice genome were inputted into software MCScanX to analyze the syntenic relationship [54] and visualized using CIRCOS (http://circos.ca/).

\section{Expression patterns of $P P R$ genes in various tissues and different stresses}

To study expression patterns of rice $P P R$ genes, the RNA-seq data were downloaded from the NCBI and RGAP. These data contained a wide range of developmental stages of rice, including shoots, leaves-20 days, pre and post-emergence inflorescence, anther, pistil, seed-5 DAP (Day After Pollination), seed-10 DAP, embryo-25 DAP, and endosperm-25 DAP. The gene expression data under different stresses(phosphate stress, cold stress, drought/salinity stress and rice stripe virus stress) were downloaded from NCBI (SRA097415, SRP026336, GSE60287, GSM1921841GSM1921846) [42, 55-57] and DDBJ (DNA Data Bank of Japan) Sequence Read Archive (DRA001092) [58]. In addition, the RNA-seq data of rice under blast infection and bacterial blight disease were downloaded from public data $[59,60]$. The RNA-seq data were reanalyzed and were $\log 2$ transformed. Heat map representing hierarchical clustering was created by MeV4.9 (MultiExperiment Viewer) software with the log-transformed values.

\section{Stem-loop RT-PCR and real-time PCR analysis}

Total RNA was isolated using TRIzol (Takara, Dalian, China) reagent from collected samples. RNase-free DNase was used to degrade DNA from total RNA at $37{ }^{\circ} \mathrm{C}$ for $30 \mathrm{~min}$. For mRNA reverse transcriptions, the first strand cDNA derived from mRNA was synthesized from $1 \mu \mathrm{g}$ total RNA using RevertAid First Strand cDNA Synthesis Kit (Fermentas, USA) according to the manufacturer's instructions. For miRNA validation, $1 \mu \mathrm{g}$ of total RNA was reverse-transcribed using miRNA-specific stem-loop primers for reverse transcription of miRNA. The reactions were incubated for $30 \mathrm{~min}$ at $16^{\circ} \mathrm{C}$, followed by 60 cycles of $30{ }^{\circ} \mathrm{C}$ for $30 \mathrm{~s}, 42^{\circ} \mathrm{C}$ for $30 \mathrm{~s}$ and $50{ }^{\circ} \mathrm{C}$ for $1 \mathrm{~s}$. The reactions were terminated by heating at $70{ }^{\circ} \mathrm{C}$ for $5 \mathrm{~min}$. All stem-loop primers were designed according to VarkonyiGasic et al. [61].

Quantitative real-time PCR (qRT-PCR) was carried out by SYBR-green fluorescence with an ABI StepOnePlus Real-Time PCR System. U6 snRNA and $\beta$-actin were used as internal control for miRNA and mRNA qRT-PCR analysis, respectively. All cDNAs were diluted 10 times and $1 \mu \mathrm{l}$ diluted product was mixed with $5 \mu \mathrm{l}$ of $2 \times$ SYBR reaction mix and $0.2 \mu \mathrm{M}$ primers in a $10 \mu \mathrm{l}$ volume reaction system. The PCR conditions were $30 \mathrm{~s}$ at $95{ }^{\circ} \mathrm{C}$, followed by 40 cycles of $10 \mathrm{~s}$ at $95{ }^{\circ} \mathrm{C}, 30 \mathrm{~s}$ at $56^{\circ} \mathrm{C}$ and $15 \mathrm{~s}$ at $72{ }^{\circ} \mathrm{C}$. Four replicates were performed for each sample. After the amplification, the melting curve was determined for specific product. Three biological replicates for each sample were performed for each sample. The relative expression levels were calculated using a ${ }^{\Delta \Delta} \mathrm{CT}$ method and the melting curve was carried out for each PCR product to avoid nonspecific amplification. All primers used in this study are listed in Additional file 1: Table S6.

\section{Promoter sequence analysis for potential cis-regulatory elements}

To analyze cis-elements in the PPR gene promoters, $1.5 \mathrm{~kb} 5^{\prime}$ upstream region sequences were downloaded from the RAP-DB database. The sequences were analyzed using PlantCARE databases (http://bioinformatics.psb.ugent.be/webtools/plantcare/html/) to find the potential cis-acting regulatory elements.

\section{Subcellular localization of one PPR protein}

All protein sequences were analyzed by TargetP 1.1 [37] and Predotarv.1.04 [38] to predict their subcellular localization in the study. To verify the subcellular localization of PPR proteins, the complete CDS without stop codons were amplified and inserted in front of the green fluorescence protein (GFP) coding sequence in the HPT-GFP vector. The PPR-GFP fusion proteins were expressed under the control of the CaMV 35S promoter in rice protoplasts. GFP fluorescence was visualized with a confocal laser scanning microscope with excitation wave lengths at $488 \mathrm{~nm}$ and emission wave lengths at $509 \mathrm{~nm}$. The mitochondria were stained with MitoTracker Red CMXRos (Invitrogen, Carlsbad, CA, USA), whose excitation and emission wave lengths are 579 and $599 \mathrm{~nm}$, respectively.

\section{Additional files}

Additional file 1: Table S1. The general information of PPR genes in rice genome. Table S2. PPR genes subcellular location results in rice by TargetP and Predotar. Table S3. PPR genes as miRNA targets in rice. Table S4. FPKM values of PPR genes in rice various organs and tissues. Table S5. RNA-seq data of PPR genes under different biotic and abiotic stresses. Table S6. Primers used in the study. (ZIP $805 \mathrm{~kb}$ )

Additional file 2: Figure S1. Structures of PPR proteins and consensus sequence of PPR motif in rice. (A) Typical structures of PPR proteins in rice. The number of motifs in each protein can vary from 2 to 28 in rice. (B) The consensus sequence of 10 PPR motif in rice. The overall height of each stack indicates the conservation of the sequence at that position and the bit score indicates the relative frequency of the corresponding acid. The lengths of the motifs can be estimated using the scale at the bottom. Figure S2. Distribution of PPR genes in rice chromosomes. The 491 PPR genes are widely and unevenly distributed on all 12 chromosomes of rice. Figure S3. Exon/intron structures of the PPR genes in rice. Yellow boxes represent exons, and black lines represent introns. Upstream or downstream regions are indicated by blue boxes. The sizes of exons and introns can be estimated using the scale at the bottom. Figure S4. Phylogenetic relationship of the PLS subgroup genes in rice and other species. Evolutionary relationships of PLS subgroup genes from rice, Arabidopsis, moss, tomato, and foxtail millet. The genes whose IDs start with LOC represent rice gene, AT represents Arabidopsis, Pp represents moss, Solyc represents tomato, and Seita represents foxtail millet. Figure S5. Expression patterns of PPR genes in different rice tissues. The FPKM expression values from RGAP of PPR genes at various developmental stages 
were $\log 2$ transformed, and a heat map was generated using the MeV4.9 software. Samples are indicated at the top of each lane: shoots, leaves20 days, pre/post-emergence inflorescence (pre-El, post-El), anther, pistil, seed-5 DAP, seed-10 DAP, embryo- 25 DAP and endosperm- 25 DAP. The color scale (representing average log2 signal values) is shown at the top. (ZIP $6622 \mathrm{~kb})$

\section{Abbreviations}

CDS: Coding sequence; CMS: Cytoplasmic male sterility; CRISPR: Clustered regularly interspaced short palindromic repeats; FPKM: Fragments per kilobase of transcript per million mapped reads; GFP: Green fusion proteins; MCScanX: Multiple collinearity scan toolkit; MeV: MultiExperiment viewer; miRNA: MicroRNA; NCBI: National Center for Biotechnology Information; PPR: Pentatricopeptide-repeat; qRT-PCR: Quantitative real-time PCR; RAPDB: Rice annotation project database; RF: Restorer of fertility; RGAP: Rice genome annotation project

\section{Acknowledgements}

We acknowledge M.S. Xingguo Huang (Wuhan Wuda Tianyuan Bio-Tech Co.,LTD) for kindly providing rice seeds and Dr. Songtao Gui for assistance in pictures drawing.

\section{Funding}

This work was supported by National Nature Science Foundation of China (31471464) and "973" Program of China (2013CB126900). The funding body didn't participate in the design of the study and collection, analysis, and interpretation of data and in writing the manuscript.

\section{Availability of data and materials}

The datasets generated analyzed during the current study are available in the NCBI, DDBJ and supplement material form public papers. These datasets were derived from the following public domain resources: https://www.ncbi.nlm.nih.gov/sra/?term=SRA097415[42] https://www.ncbi.nlm.nih.gov/sra/?term $=$ SRP026336[51] https://www.ncbi.nlm.nih.gov/geo/query/acc.cgi?acc=GSE60287[52] https://www.ncbi.nlm.nih.gov/geo/query/acc.cgi?acc=GSE74498[53] http://ddbj.nig.ac.jp/DRASearch/query?acc=DRA001092[54] https://doi.org/10.1371/journal.pone.0051609.s003[55] https://doi.org/10.1371/journal.pone.0137360.s012[56]

\section{Authors' contributions}

YD, GC and JH conceived and designed the experiments. GC and YZ performed the experiments. GC and JH analyzed the data and wrote the manuscript. YD modified the manuscript. All authors read and approved the final manuscript.

\section{Ethics approval and consent to participate} Not applicable.

\section{Consent for publication}

Not applicable.

\section{Competing interests}

The authors declare that they have no competing interests.

\section{Publisher's Note}

Springer Nature remains neutral with regard to jurisdictional claims in published maps and institutional affiliations.

\section{Author details}

${ }^{1}$ State Key Laboratory of Hybrid Rice, Department of Genetics, College of Life Sciences, Wuhan University, Wuhan 430072, China. ${ }^{2}$ Key Laboratory of Biology and Genetic Improvement of Oil Crops, Ministry of Agriculture, Oil Crops Research Institute of the Chinese Academy of Agricultural Sciences, Wuhan 430062, China.
Received: 29 August 2018 Accepted: 18 September 2018 Published online: 01 October 2018

\section{References}

1. Barkan A, Small I. Pentatricopeptide repeat proteins in plants. Annu Rev Plant Biol. 2014;65:415-42.

2. Schmitz-Linneweber C, Small I. Pentatricopeptide repeat proteins: a socket set for organelle gene expression. Trends Plant Sci. 2008;13(12):663-70.

3. Small ID, Peeters N. The PPR motif - a TPR-related motif prevalent in plant organellar proteins. Trends Biochem Sci. 2000;25(2):46-7.

4. Lurin C, Andres C, Aubourg S, Bellaoui M, Bitton F, Bruyere C, et al. Genomewide analysis of Arabidopsis pentatricopeptide repeat proteins reveals their essential role in organelle biogenesis. Plant Cell. 2004;16(8):2089-103.

5. Okuda K, Myouga F, Motohashi R, Shinozaki K, Shikanai T. Conserved domain structure of pentatricopeptide repeat proteins involved in chloroplast RNA editing. Proc Natl Acad Sci U S A. 2007;104(19):8178-83.

6. Hayes ML, Dang KN, Diaz MF, Mulligan RM. A conserved glutamate residue in the C-terminal deaminase domain of pentatricopeptide repeat proteins is required for RNA editing activity. J Biol Chem. 2015;290(16):10136-42.

7. Ichinose M, Tasaki E, Sugita C, Sugita M. A PPR-DYW protein is required for splicing of a group II intron of cox1 pre-mRNA in Physcomitrella patens. Plant J. 2012;70(2):271-8.

8. Pfalz J, Bayraktar OA, Prikryl J, Barkan A. Site-specific binding of a PPR protein defines and stabilizes $5^{\prime}$ and $3^{\prime}$ mRNA termini in chloroplasts. EMBO J. 2009;28(14):2042-52

9. Yin Q, Cui Y, Zhang G, Zhang H, Wang X, Yang Z. The Arabidopsis pentatricopeptide repeat protein PDM1 is associated with the intergenic sequence of S11-rpoA for rpoA monocistronic RNA cleavage. Chin Sci Bull. 2012;57(26):3452-9.

10. Tang H, Luo D, Zhou D, Zhang Q, Tian D, Zheng X, et al. The rice restorer Rf4 for wild-abortive cytoplasmic male sterility encodes a mitochondriallocalized PPR protein that functions in reduction of WA352 transcripts. Mol Plant. 2014;7(9):1497-500.

11. Tavares-Carreon F, Camacho-Villasana Y, Zamudio-Ochoa A, Shingu-Vazquez M, Torres-Larios A, Perez-Martinez X. The pentatricopeptide repeats present in Pet309 are necessary for translation but not for stability of the mitochondrial COX1 mRNA in yeast. J Biol Chem. 2008:283(3):1472-9.

12. Shen C, Zhang D, Guan Z, Liu Y, Yang Z, Yang Y, et al. Structural basis for specific single-stranded RNA recognition by designer pentatricopeptide repeat proteins. Nat Commun. 2016;7:11285

13. Fujii S, Suzuki T, Giege P, Higashiyama T, Koizuka N, Shikanai T. The restorerof-fertility-like 2 pentatricopeptide repeat protein and RNase $P$ are required for the processing of mitochondrial orf291 RNA in Arabidopsis. Plant J. 2016; 86(6):504-13.

14. Wang W, Wu Y, Messing J. Genome-wide analysis of pentatricopeptiderepeat proteins of an aquatic plant. Planta. 2016;244(4):893-9.

15. Cheng S, Gutmann B, Zhong X, Ye Y, Fisher MF, Bai F, et al. Redefining the structural motifs that determine RNA binding and RNA editing by pentatricopeptide repeat proteins in land plants. Plant J. 2016;85(4):532-47. http://www.plantppr.com/

16. Ding A, Li L, Qu X, Sun T, Chen Y, Zong P, et al. Genome-wide identification and bioinformatic analysis of PPR gene family in tomato. Hereditas(Beijing). 2014;36(1):77-84.

17. Liu JM, Xu ZS, Lu PP, Li WW, Chen M, Guo CH, et al. Genome-wide investigation and expression analyses of the pentatricopeptide repeat protein gene family in foxtail millet. BMC Genomics. 2016;17(1):840.

18. Kim SR, Yang Jl, Moon S, Ryu CH, An K, Kim KM, et al. Rice OGR1 encodes a pentatricopeptide repeat-DYW protein and is essential for RNA editing in mitochondria. Plant J. 2009;59(5):738-49.

19. Klein RR, Klein PE, Mullet JE, Minx P, Rooney WL, Schertz KF. Fertility restorer locus Rf1 of sorghum (Sorghum bicolor L.) encodes a pentatricopeptide repeat protein not present in the colinear region of rice chromosome 12. Theor Appl Genet. 2005;111(6):994-1012.

20. Jo YD, Ha Y, Lee JH, Park M, Bergsma AC, Choi Hl, et al. Fine mapping of restorer-of-fertility in pepper (Capsicum annuum L.) identified a candidate gene encoding a pentatricopeptide repeat (PPR)-containing protein. Theor Appl Genet. 2016;129(10):2003-17.

21. Gillman JD, Bentolila S, Hanson MR. The petunia restorer of fertility protein is part of a large mitochondrial complex that interacts with transcripts of the CMS- associated locus. Plant J. 2007;49(2):217-27. 
22. Wang Z, Zou Y, Li X, Zhang Q, Chen L, Wu H, et al. Cytoplasmic male sterility of rice with Boro II cytoplasm is caused by a cytotoxic peptide and is restored by two related PPR motif genes via distinct modes of mRNA silencing. Plant Cell. 2006;18(3):676-87.

23. Kazama T, Nakamura T, Watanabe M, Sugita M, Toriyama K. Suppression mechanism of mitochondrial ORF79 accumulation by Rf1 protein in BT-type cytoplasmic male sterile rice. Plant J. 2008;55(4):619-28.

24. Hu J, Wang K, Huang W, Liu G, Gao Y, Wang J, et al. The rice pentatricopeptide repeat protein RF5 restores fertility in Hong-Lian cytoplasmic male-sterile lines via a complex with the glycine-rich protein GRP162. Plant Cell. 2012;24(1):109-22.

25. Jiang SC, Mei C, Liang S, Yu YT, Lu K, Wu Z, et al. Crucial roles of the pentatricopeptide repeat protein SOAR1 in Arabidopsis response to drought, salt and cold stresses. Plant Mol Biol. 2015;88(4-5):369-85.

26. Zsigmond L, Rigo G, Szarka A, Szekely G, Otvos K, Darula Z, et al. Arabidopsis PPR40 connects abiotic stress responses to mitochondrial electron transport. Plant Physiol. 2008;146(4):1721-37.

27. Liu Y, He J, Chen Z, Ren X, Hong X, Gong Z. ABA overly-sensitive 5 (ABO5), encoding a pentatricopeptide repeat protein required for cis-splicing of mitochondrial nad2 intron 3, is involved in the abscisic acid response in Arabidopsis. Plant J. 2010;63(5):749-65.

28. Yuan H, Liu D. Functional disruption of the pentatricopeptide protein SLG affects mitochondrial RNA editing, plant development, and responses to abiotic stresses in Arabidopsis. Plant J. 2012;70(3):432-44.

29. Laluk K, Abuqamar S, Mengiste T. The Arabidopsis mitochondria-localized pentatricopeptide repeat protein PGN functions in defense against necrotrophic fungi and abiotic stress tolerance. Plant Physiol. 2011;156(4):2053-68.

30. Zhu Q, Dugardeyn J, Zhang C, Muhlenbock P, Eastmond PJ, Valcke R, et al. The Arabidopsis thaliana RNA editing factor SLO2, which affects the mitochondrial electron transport chain, participates in multiple stress and hormone responses. Mol Plant. 2014;7(2):290-310.

31. Gong X, Su Q, Lin D, Jiang Q, Xu J, Zhang J, et al. The rice OsV4 encoding a novel pentatricopeptide repeat protein is required for chloroplast development during the early leaf stage under cold stress. J Integr Plant Biol. 2014;56(4):400-10.

32. Wu L, Wu J, Liu Y, Gong X, Xu J, Lin D, et al. The Rice Pentatricopeptide repeat gene TCD10 is needed for chloroplast development under cold stress. Rice. 2016;9(1):67.

33. O'Toole N, Hattori M, Andres C, lida K, Lurin C, Schmitz-Linneweber C, et al. On the expansion of the pentatricopeptide repeat gene family in plants. Mol Biol Evol. 2008;25(6):1120-8.

34. Sugita $M$, Ichinose $M$, Ide $M$, Sugita $C$. Architecture of the PPR gene family in the moss Physcomitrella patens. RNA Biol. 2013;10(9):1439-45.

35. Crooks GE, Hon G, Chandonia JM, Brenner SE. WebLogo: a sequence logo generator. Genome Res. 2004;14(6):1188-90.

36. Xing H, Fu X, Yang C, Tang X, Guo L, Li C, et al. Genome-wide investigation of pentatricopeptide repeat gene family in poplar and their expression analysis in response to biotic and abiotic stresses. Sci Rep. 2018;8(1):2817.

37. Emanuelsson O, Nielsen H, Brunak S, von Heijne G. Predicting subcellular localization of proteins based on their $\mathrm{N}$-terminal amino acid sequence. J Mol Biol. 2000;300(4):1005-16.

38. Small I, Peeters N, Legeai F, Lurin C. Predotar: a tool for rapidly screening proteomes for N-terminal targeting sequences. Proteomics. 2004;4(6):1581-90.

39. Zhang H, Hu J, Qian Q, Chen H, Jin J, Ding Y. Small RNA profiles of the Rice PTGMS line Wuxiang $S$ reveal miRNAs involved in fertility transition. Front Plant Sci. 2016;7:514.

40. Jeong D-H, Green PJ. The role of rice microRNAs in abiotic stress responses. J Plant Biol. 2013;56(4):187-97.

41. Yan J, Zhang H, Zheng Y, Ding Y. Comparative expression profiling of miRNAs between the cytoplasmic male sterile line MeixiangA and its maintainer line MeixiangB during rice anther development. Planta. 2015;241(1):109-23.

42. Shankar R, Bhattacharjee A, Jain M. Transcriptome analysis in different rice cultivars provides novel insights into desiccation and salinity stress responses. Sci Rep. 2016;6:23719.

43. Lescot M, Dehais $P$, Thijs $G$, Marchal $K$, Moreau $Y$, Van de Peer $Y$, et al. PlantCARE, a database of plant cis-acting regulatory elements and a portal to tools for in silico analysis of promoter sequences. Nucleic Acids Res. 2002;30(1):325-7.

44. Prikryl J, Rojas M, Schuster G, Barkan A. Mechanism of RNA stabilization and translational activation by a pentatricopeptide repeat protein. Proc Natl Acad Sci U S A. 2011;108(1):415-20.
45. Williams-Carrier R, Kroeger T, Barkan A. Sequence-specific binding of a chloroplast pentatricopeptide repeat protein to its native group II intron ligand. RNA. 2008;14(9):1930-41.

46. Holzle A, Jonietz C, Torjek O, Altmann T, Binder S, Forner J. A restorer of fertility-like PPR gene is required for $5^{\prime}$-end processing of the nad4 mRNA in mitochondria of Arabidopsis thaliana. Plant J. 2011;65(5):737-44.

47. Xiao H, Xu Y, Ni C, Zhang Q, Zhong F, Huang J, et al. A rice dual-localized pentatricopeptide repeat protein is involved in organellar RNA editing together with OsMORFs. J Exp Bot. 2018;69(12):2923-36.

48. KOMORI T, IMASEKI H. Transgenic rice hybrids that carry the Rf-1 gene at multiple loci show improved fertility at low temperature. Plant Cell Environ. 2005;28(4):425-31.

49. Jeong DH, Park S, Zhai J, Gurazada SG, De Paoli E, Meyers BC, et al. Massive analysis of rice small RNAs: mechanistic implications of regulated microRNAs and variants for differential target RNA cleavage. Plant Cell. 2011; 23(12):4185-207.

50. Tan J, Tan Z, Wu F, Sheng P, Heng Y, Wang X, et al. A novel chloroplastlocalized pentatricopeptide repeat protein involved in splicing affects chloroplast development and abiotic stress response in rice. Mol Plant. 2014;7(8):1329-49.

51. Tran LS, Nakashima K, Sakuma Y, Simpson SD, Fujita Y, Maruyama K, et al. Isolation and functional analysis of Arabidopsis stress-inducible NAC transcription factors that bind to a drought-responsive cis-element in the early responsive to dehydration stress 1 promoter. Plant Cell. 2004;16(9):2481-98.

52. Baker SS, Wilhelm KS, Thomashow MF. The 5'-region of Arabidopsis thaliana cor15a has cis-acting elements that confer cold-, drought- and ABAregulated gene expression. Plant Mol Biol. 1994;24(5):701-13.

53. Kumar S, Stecher G, Tamura K. MEGA7: molecular evolutionary genetics analysis version 7.0 for bigger datasets. Mol Biol Evol. 2016;33(7):1870-4.

54. Wang $Y$, Tang H, Debarry JD, Tan X, Li J, Wang $X$, et al. MCScanX: a toolkit for detection and evolutionary analysis of gene synteny and collinearity. Nucleic Acids Res. 2012;40(7):e49.

55. Yang J, Zhang F, Li J, Chen JP, Zhang HM. Integrative analysis of the microRNAome and transcriptome illuminates the response of susceptible Rice plants to Rice stripe virus. PLoS One. 2016;11(1):e0146946.

56. Secco D, Jabnoune M, Walker $H$, Shou $H$, Wu P, Poirier $Y$, et al. Spatiotemporal transcript profiling of rice roots and shoots in response to phosphate starvation and recovery. Plant Cell. 2013;25(11):4285-304.

57. Shen C, Li D, He R, Fang Z, Xia Y, Gao J, et al. Comparative transcriptome analysis of RNA-seq data for cold-tolerant and cold-sensitive rice genotypes under cold stress. J Plant Biol. 2014;57(6):337-48.

58. Oono Y, Yazawa T, Kawahara Y, Kanamori H, Kobayashi F, Sasaki H, et al. Genome-wide transcriptome analysis reveals that cadmium stress signaling controls the expression of genes in drought stress signal pathways in rice. PLoS One. 2014;9(5):e96946.

59. Bagnaresi P, Biselli C, Orru L, Urso S, Crispino L, Abbruscato P, et al. Comparative transcriptome profiling of the early response to Magnaporthe oryzae in durable resistant vs susceptible rice (Oryza sativa L.) genotypes. PLoS One. 2012;7(12):e51609.

60. Hong H, Liu Y, Zhang H, Xiao J, Li X, Wang S. Small RNAs and gene network in a durable disease resistance gene--mediated defense responses in Rice. PLoS One. 2015;10(9):e0137360.

61. Varkonyi-Gasic E, Wu R, Wood M, Walton EF, Hellens RP. Protocol: a highly sensitive RT-PCR method for detection and quantification of microRNAs. Plant Methods. 2007:3:12.

Ready to submit your research? Choose BMC and benefit from:

- fast, convenient online submission

- thorough peer review by experienced researchers in your field

- rapid publication on acceptance

- support for research data, including large and complex data types

- gold Open Access which fosters wider collaboration and increased citations

- maximum visibility for your research: over $100 \mathrm{M}$ website views per year

At BMC, research is always in progress.

Learn more biomedcentral.com/submissions 